\title{
INAPLICABILIDADES DO DIREITO NA AMAZÔNIA: POR UM DIREITO AMBIENTAL URBANÍSTICO DA AMAZÔNIA E NÃO NA AMAZÔNIA
}

\author{
Thales Maximiliano Ravena Cañete \\ Cientista Social, Bacharel em Direito, mestre pelo Programa de Pós-graduação em Direito e \\ doutor pelo Programa de Pós-graduação em Sociologia e Antropologia, ambos da Universida- \\ de Federal do Pará; professor do curso de Direito da Escola \\ Superior Madre Celeste (Ananindeua/PA). \\ Email: thales_canete@yahoo.com.br \\ Voyner Ravena Cañete \\ Antropóloga, Doutora em Ciências Socioambientais, professora dos Programas de Pós-Gra- \\ duação em "Ecologia Aquática e Pesca" (PPGEAP) e "Sociologia e Antropologia" (PPGSA), \\ ambos da Universidade Federal do Pará. \\ Email: ravenacanete@gmail.com
}

\begin{abstract}
RESUMO
Este artigo tem por objetivo demonstrar a parcial inaplicabilidade do ordenamento jurídico do Direito Ambiental Urbanístico na Amazônia, na medida em que este se baseia em conceitos advindos da realidade sulcentro-oeste, os quais desconsideram as comunidades amazônicas e seu modo de vida socioambiental. Usa como base argumentativa as reflexões de Bourdieu, especialmente o conceito de campo e capital simbólico, assim como evidencia a importância de relativizar o binômio rural/urbano dentro do contexto amazônico. A metodologia de pesquisa empregada configurou-se em extensas revisões bibliográficas sobre a região amazônica e no conceito de urbano e rural empregado nesta região, assim como na reinterpretação de dados estatísticos sobre essa região, potencializados por vivências em campo de seus autores, com pesquisas em diversos municípios amazônicos, em especial na região do rio Purus, baixo Tocantins e litoral paraense.
\end{abstract}

Palavras chave: Direito Ambiental Urbanístico; modo de vida socioambiental; Amazônia. 
INAPLICABILITIES OF THE LAW IN THE AMAZON: FOR AN URBAN
ENVIRONMENTAL LAW OF THE AMAZON AND NOT IN THE $A M A Z O N$

\begin{abstract}
This article aims to demonstrate the partial inapplicability of the legal framework of urban environmental law in the Amazon, since the concepts oh this legal discipline derive from Brazil's south-central-west reality, which disregard Amazonian communities and their socio-environmental way of life. It used as an argumentative basis the reflections of Bourdieu, especially the concept of field and symbolic capital, as well as shows the importance of relativizing the rural / urban binomial within the Amazonian context. The research methodology employed was extensive bibliographical reviews of the Brazilian amazon and the urban and rural concept used in it, as well as in the re-interpretation of statistical data about this region, enhanced by experiences in the field of its authors, with researches in several Amazonian municipalities, especially in the region of the Purus river, low Tocantins and coast of Para.
\end{abstract}

Keywords: urban environmental law; Socio-environmental way of life; Brazilian amazon. 


\section{INTRODUÇÃO}

A diversidade sociocultural das populações amazônicas encontrase intrinsicamente ligada à diversidade ambiental dessa região. Nas últimas décadas, suas populações nativas transformaram-se em protagonistas na proteção do meio ambiente, sendo genericamente denominadas de "populações tradicionais" (CASTRO e MARIN, 1993). Estas apresentam um modo de vida diferenciado da sociedade nacional, desenvolvendo ao longo dos séculos modos de vida específicos e variados, mas, com a particularidade de haver uma relação relativamente harmônica com o meio ambiente, enquanto a sociedade nacional desenvolveu um modo de vida no qual o meio ambiente é subjugado à vontade humana, não considerando nenhum tipo de limite ou capacidade de resiliência (DIEGUES, 1997).

Considerando-se que nas duas últimas décadas o Brasil se transformou de um país marcadamente agrário em um país urbano, pensar as implicações desse novo cenário para a Amazônia torna-se imperioso. Este ensaio tem por objetivo demonstrar a parcial inaplicabilidade do ordenamento jurídico do Direito Ambiental Urbanístico na Amazônia, na medida em que este se baseia em conceitos advindos da realidade SulCentro-Oeste, os quais desconsideram as comunidades amazônicas e seu modo de vida socioambiental (LIMA E POZZOBON, 2005; MAUÉS, 1999). Usa como base argumentativa as reflexões de Bourdieu (2004), especialmente o conceito de campo e capital simbólico, assim como evidencia a importância de relativizar o binômio rural/urbano (ALMEIDA, 2008; LIMA E POZZOBON, 2005; VEIGA, 2002) dentro do contexto amazônico. A metodologia de pesquisa empregada configurou-se em extensas revisões bibliográficas sobre a região amazônica e no conceito de urbano e rural empregado nesta região, assim como na reinterpretação de dados estatísticos sobre esse local. Estes dados são potencializados por extensa vivência em campo de seus autores, com pesquisas em diversos municípios amazônicos, em especial na região do rio Purus, baixo Tocantins e litoral paraense.

Assim, este artigo está estruturado nesta introdução, seguida de mais três seções e das considerações finais. A primeira seção tem por objetivo apresentar o instrumental teórico no qual este trabalho se apoia para pensar sobre a ideia de direito e região, visualizando-os como socialmente construídos. A segunda seção responsabiliza-se por apresentar, de maneira breve, a realidade socioambiental amazônica e um pouco do 
perfil de suas comunidades, detalhando o conceito de população tradicional, especificando-o no caso da Amazônia. A terceira seção tem como escopo a relativização da dicotomia rural/urbano dentro do contexto amazônico, deixando para as considerações finais as implicações relativas às reflexões construídas por este texto.

\section{BOURDIEU E A NOÇÃO DE CAMPO JURÍDICO E REGIÃO}

Segundo Bourdieu, o funcionamento do campo jurídico seria responsável pela construção de uma prática e um discurso jurídico, ao passo que a lógica específica deste campo está duplamente determinada:

por um lado, pelas relações de força específicas que lhe conferem a sua estrutura e que orientam as lutas de concorrência ou, mais precisamente, os conflitos de competência que nele têm lugar e, por outro lado, pela lógica interna das obras jurídicas que delimitam em cada momento o espaço dos possíveis e, deste modo, o universo das soluções propriamente jurídicas (BOURDIEU, 2004, p. 211).

Assim, Bourdieu chama a atenção para a influência que a estrutura social exerce na construção da realidade jurídica de uma maneira geral, mais especificamente a influência que as relações de força dentro do próprio campo exercem na estrutura e funcionamento do mesmo, evidenciando os conflitos de competência existentes dentro dele próprio. $\mathrm{O}$ autor também demonstra como a lógica interna do campo jurídico acaba por delimitar o seu espaço de atuação, ou seja, "o universo das soluções propriamente jurídicas” (BOURDIEU, 2004, p. 211).

Mais adiante, Bourdieu amplia a noção de campo jurídico, entendendo-o como

o lugar de concorrência pelo monopólio do direito de dizer o direito, quer dizer, a boa distribuição (nomos) ou a boa ordem, na qual se defrontam agentes investidos de competência ao mesmo tempo social e técnica que consiste essencialmente na capacidade reconhecida de interpretar (de maneira mais ou menos livre ou autorizada) um corpus de textos que consagram a visão legítima, justa, do mundo social (BOURDIEU, 2004, p. 212).

Este conceito de campo jurídico abre a possibilidade de se construir algumas reflexões. Uma delas refere-se ao fato de que o autor 
em pauta chama a atenção para como a sociedade é produto dela mesma, encontrando-se em um eterno processo de reconstrução. No caso do campo jurídico, Bourdieu observa que este é relativamente independente, ou seja, sofre influências externas e internas na constituição da sua estrutura organizacional, consequentemente, no produto que resulta deste campo. Assim, o ordenamento jurídico sofre influência não somente das disputas e conflitos sociais de maneira geral, mas também das disputas e conflitos dentro do próprio campo jurídico, na eterna e mutável "concorrência pelo monopólio de dizer o direito" (p. 212).

Portanto, uma das principais mensagens passíveis de se apresentar como sendo o centro das reflexões de Bourdieu sobre o campo jurídico, seria a afirmativa de que o Direito constrói-se como uma espécie de campo, no qual existem disputas e conflitos de toda ordem (econômica, social etc), tanto internamente (dentro do próprio campo) como externamente (advinda de outros campos e da realidade social de uma maneira mais geral). Vale observar que, para Bourdieu, é a competência que garante aos agentes jurídicos o poder de “... controlar o acesso ao campo jurídico, determinando os conflitos que merecem estar nele" (p. 233).

Com efeito, Bourdieu demonstra como o campo jurídico pode ser socialmente construído e como ele está submerso nas disputas e conflitos da realidade social e da própria realidade de seu campo específico. O autor também evidencia como esse campo acaba por exercer sua influência em outros campos da realidade social, configurando-se como uma estrutura estruturante ${ }^{1}$.

Dentre estes campos da realidade social, sobre os quais o campo jurídico exerce influência, encontra-se a ideia de região, sendo que esta também exerce influência na produção do campo jurídico. Nesse sentido, Bourdieu (1989) observa como a ideia de região, tal como outros componentes do mundo social, é construída socialmente. Nas palavras do autor:

a realidade, neste caso, é social de parte a parte e as classificações mais naturais apoiam-se em características que nada têm de natural e que são, em grande parte, produto de uma imposição arbitrária, quer dizer, de um estado anterior da relação de forças no campo das lutas pela delimitação legítima (1989, p.115).

Consequentemente, a ideia de região e o campo jurídico irão

1 Para mais detalhes, consultar o livro de Bourdieu, "O poder Simbólico", mais especificamente em seu primeiro capítulo intitulado "Sobre o Poder Simbólico" (BOURDIEU, 1989, p.7-17). 
influenciar-se, fazendo com que as delimitações de uma região sejam produtos de um ato jurídico "que produz a diferença cultural do mesmo modo que é produto desta" (BOURDIEU, 1989, p. 115), fazendo com que se tenha em mente o fato de que

O regionalismo (ou o nacionalismo) é apenas um caso particular das lutas propriamente simbólicas em que os agentes estão envolvidos quer individualmente e em estado de dispersão, quer coletivamente e em estado de organização, e em que está em jogo a conservação ou a transformação das relações de forças simbólicas e das vantagens correlativas, tanto econômicas como simbólicas; ou, se se prefere, a conservação ou a transformação das leis de formação dos preços materiais ou simbólicos ligados às manifestações simbólicas (objetivas ou intencionais) da identidade social. Nesta luta pelos critérios de avaliação legítima, os agentes empenham interesses poderosos, vitais por vezes, na medida em que é o valor da pessoa enquanto reduzida socialmente a sua identidade social que está em jogo. (p. 124)

Em outras palavras, como a ideia de região constitui-se em algo socialmente construído, esta mesma ideia estará submersa em disputas e conflitos sociais, fazendo com que o monopólio de delimitar as regiões e fronteiras ${ }^{2}$ demonstre que o que

está em jogo é o poder de impor uma visão do mundo social através dos princípios de divisão que, quando se impõem ao conjunto do grupo, realizam sentido e o consenso sobre o sentido e, em particular, sobre a identidade e a unidade do grupo, que fazem a realidade da unidade e da identidade do grupo (p. 113).

Assim, através da ideia de região, pode-se refletir acerca da construção do campo jurídico no sentido de que este será influenciado na medida em que considera a ordem hierárquica existente dentro da ideia de região e vice-versa. Desta forma, uma região que é nacionalmente identificada como pouco influente dentro da arena de disputa nacional, pouca influência terá no campo jurídico ou, nas palavras de Bourdieu, no "direito de dizer o direito", assim como o ator social dentro do campo jurídico que estiver ocupando um lugar raso na ordem hierárquica pouca influência terá no processo de ditar as fronteiras e identidades regionais.

2 Ou, nas palavras de Bourdieu (1989, p. 113): o "monopólio de fazer ver e fazer crer, de dar a conhecer e de fazer reconhecer, de impor a definição legítima das divisões do mundo social e, por este meio, de fazer e de desfazer os grupos". 


\section{O CENÁRIO SOCIOAMBIENTAL DAS POPULAÇÕES AMAZÔNICAS: A DIVERSIDADE EM PAUTA}

Em virtude de apresentar-se como uma floresta tropical, a Amazônia configura-se como detentora de uma das maiores diversidades do planeta, tanto ambiental, como biológica e social. Diversos tipos de solos, fauna, flora, etnias e culturas encontram-se presentes na realidade amazônica (Meirelles Filho, 2004).

Maués (1999) descreve a sociodiversidade da Amazônia, chamando a atenção para como ela se expressa através do

grande número de povos indígenas, com diferentes idiomas e costumes, constituindo uma etnodiversidade que deve ser preservada pelo respeito à vida e ao modo de vida dessas pessoas, bem como para o enriquecimento do patrimônio cultural da humanidade (MAUÉS, 1999 p. 58).

Mais adiante, Maués (1999) inclui dentro dessa sociodiversidade

populações regionais não índias, entre as quais se incluem também algumas categorias étnicas - caboclos, seringueiros, pescadores, camponeses, garimpeiros, ribeirinhos, negros remanescentes de quilombos, urbanitas, pessoas de todas as classes e categorias sociais - que portam uma diversidade muito grande de formas de organização social e de patrimônio cultural que, por sua vez, também merecem todo o respeito (MAUÉS, 1999 p. 58).

Tamanha diversidade etnossociocultural acima evidenciada pode ser resumida no termo população tradicional. Neste trabalho será utilizada a terminologia população tradicional amazônica, para que não seja confundida com populações tradicionais de outras regiões, que, apesar de apresentarem a mesma essência socioambiental, detêm outras características que as diferenciam entre si.

Este empreendimento entende como população tradicional aquelas que apresentam as seguintes características: a) a sua forma de reprodução socioeconômica deve ser marcada por uma lógica consuntiva, portanto, de produção e consumo onde o excedente é comercializado com o mercado, mas não se constitui em fator determinante das escolhas do grupo (LIMA e POZZOBON, 2005; ARRUDA, 1999); b) devem apresentar um modus 
vivendi de integração com a natureza (DIEGUES, 1993, 1994; SANTILLI, 2004, 2005); c) suas atividades de reprodução social e econômica são marcadas por um baixo impacto ambiental (ARRUDA, 1999; LIMA e POZZOBON, 2005; DIEGUES, 1993, 1994); d) baixa integração com o mercado (LIMA e POZZOBON, 2005; ARRUDA, 1999); e) falta de documentos que legitimem a sua propriedade (ARRUDA, 1999) e consequente fragilidade social no que concerne à garantia de suas terras; f) direta dependência dos recursos naturais locais, tanto no sentido de conseguirem alguma renda que lhes dê um mínimo de acesso a objetos e gêneros alimentícios diversos, como no sentido de sua subsistência através do consumo direto dos mesmos (LIMA e POZZOBON, 2005; DIEGUES, 1993, 1994; ARRUDA, 1999); g) devem autodeterminar-se como populações tradicionais (CUNHA, 1999; CUNHA e ALMEIDA, 2001; ALMEIDA, 2006; ALMEIDA 2007).

Contudo,aspopulaçõesditas “tradicionais"nãoprecisamapresentar todas estas características, mas, minimamente se autoidentificarem como um grupo culturalmente diferenciado da sociedade nacional. Com isso, estas populações exercem o seu direito internacionalmente reconhecido de autorreconhecimento ${ }^{3}$, adquirindo a possibilidade de ter acesso a outros direitos, direitos estes específicos destas populações, que foram amplamente declarados através do ordenamento jurídico pátrio (Lei 9985, art 225 da C.F., decreto $n^{\circ} 6040$, e diversos outros). Vale ressaltar que este é um termo em construção, sendo criado pela sociedade nacional para classificar outras sociedades. Dessa forma, nem sempre essas populações se denominam tradicionais, mas, sim, são denominadas por outros atores sociais como tais.

Com efeito, a abundância e diversidade que marcam o meio ambiente, assim como o cenário social da Amazônia, demandam um olhar mais próximo capaz de traduzir as especificidades locais encontradas. Consequentemente, é assim que o campo jurídico deveria visualizar as populações tradicionais, colocando-as mais próximas de si mesmo ou da possibilidade de possuir o "direito de dizer o direito". Contudo, como se verá a seguir, essa aproximação ou mesmo participação das populações tradicionais em relação ao campo jurídico e seu respectivo ordenamento hierárquico é praticamente inexistente. Assim, as populações tradicionais dificilmente são consideradas quando da tomada de decisão na atuação deste campo.

3 Convenção 169 da OIT. 


\section{A NECESSIDADE DE RELATIVIZAÇÃO DO BINÔMIO RURAL/ URBANO}

Demonstrou-se acima como a realidade amazônica é extremamente diversificada em sua cultura, meio ambiente, grupos sociais, modos de vida, religiosidade, enfim, em uma série de fatores e variáveis que diversificam as populações tradicionais amazônicas. Essa diversidade se espraia até as cidades, contudo, nem sempre assumindo o modo de vida urbano, que finda incorporando práticas tradicionais. Assim, as cidades amazônicas assumem um aspecto peculiar, pois são compostas por atores sociais com valores e modos de vida rurais ou socioambientais variados.

Como exemplo pode-se citar o os estudos de Souza (2009) no município de Tapauá-AM. Esta autora observa que os "moradores partem do meio rural para viver na cidade, não (...) motivados por atração da vida urbana ou interesse econômico" (p.98), mas, sim, pela facilidade que a cidade traz no acesso a diversos serviços públicos, como seguridade social, saúde, educação, entre outros, quase inexistentes na área rural ou com um custo muito alto de acesso.

Com efeito, Souza (2009) observa que, para os moradores do município de Tapauá, a mudança “(...) para a cidade não representa alteração na forma de trabalho. As atividades antes realizadas na área rural permanecem, apenas o morador rural passa a residir no meio urbano. As atividades como agricultura, extrativismo, pesca e criação são mantidas." (p. 95). Nesse sentido, no caso de Tapauá, "não foi a cidade que avançou para o campo, mas o campo que ocupou a cidade e desta forma não houve a completa urbanização, mas, pelo contrário, houve a completa ruralização" (p. 96).

Observa-se nos estudos de Souza (2009) a indicação de que a noção de urbano deve ser relativizada dentro do contexto socioambiental tão diversificado como o amazônico. Corroborando este argumento, Almeida (2008) observa que vem se tornando cada vez mais comum e constante o êxodo de populações tipicamente rurais (como ribeirinhos, extrativistas, quilombolas e até mesmo indígenas) para o espaço urbano. Nesse sentido, o referido autor corrobora a tentativa de relativização do binômio rural/urbano ao observar que:

expressões organizativas e formas de ocupação que são pensadas como intrínsecas

à área rural despontam dentro do perímetro urbano, levando os estudiosos a 
relativizarem as dicotomias rural/urbano e nômade/sedentário na caracterização das chamadas "comunidades tradicionais" e no reconhecimento de suas expressões identitárias. (p. 87).

Almeida (2008) dá continuidade ao seu texto refletindo acerca da organização sociopolítica das populações tradicionais. O autor observa que a organização sociopolítica e os diversos movimentos sociais, frutos desta, permitem às populações tradicionais transitar entre fronteiras tanto geográficas como simbólicas: os movimentos sociais agregam populações tradicionais de diversos estados da Federação, de diversas etnias, com origens tanto rural como urbana. Assim, redes de parentesco, compadrio e de sociabilidade são formadas com o intuito de abrir possibilidades a essas populações há muito esquecidas pelo governo. Com esta organização sociopolítica, as populações tradicionais conseguem reivindicar e garantir diversos direitos, legitimando o seu modo de vida. Nas palavras de Almeida (2008),

tem-se o advento de categorias que se afirmam através de uma existência coletiva, politizando não apenas as nomeações da vida cotidiana, mas também um certo modo de viver e suas práticas rotineiras no uso dos recursos naturais. A complexidade de elementos identitários, próprios de autodenominações afirmativas de culturas e símbolos, que fazem da etnia um tipo organizacional (Barth:1969), foi trazida para o campo das relações políticas, verificando-se uma ruptura profunda com a atitude colonialista homogeneizante, que historicamente apagou diferenças étnicas e a diversidade cultural, diluindo-as em classificações que enfatizavam a subordinação dos "nativos", "selvagens" e ágrafos ao conhecimento erudito do colonizador. (p. 89).

Entre as classificações “...que enfatizavam a subordinação dos "nativos", "selvagens" e ágrafos ao conhecimento erudito do colonizador" (ALMEIDA, 2008. p. 89), pode-se colocar a dicotomia entre rural e urbano, que fica cada vez mais tênue e até mesmo inútil, pois vem se diluindo à medida que as populações tradicionais, outrora vistas como exclusivamente do campo rural, adentram o espaço urbano, contudo, permanecendo com o seu modo de vida peculiar e específico. Segundo Almeida (2009), as relações econômicas também auxiliam no rompimento da barreira rural/ urbano. $\mathrm{O}$ autor cita diversos exemplos, entre eles o caso das quebradeiras de coco babaçu que fundaram na cidade de São Luis, capital do Maranhão, um entreposto comercial e de representação política que "Funciona 
no Centro Histórico e dispõe à comercialização uma linha de produtos peculiar: farinha de mesocarpo, papel reciclado com fibra de babaçu, (...) além de livros e demais publicações pertinentes ao extrativismo." (p. 93).

Assim, a partir da organização dos movimentos sociais das populações tradicionais, Almeida conclui que existe

\footnotetext{
uma luta teórica contra a força dos esquemas interpretativos dos "positivistas no direito", que sempre querem confundir etnias, minorias e/ou povos tradicionais dentro de uma noção genérica de "povo", elidindo a diversidade cultural, e contra a ação sem sujeito de esquemas inspirados nos "estruturalismos", que privilegiam e se circunscrevem às oposições simétricas entre "comum" e "individual", entre "coletivo" e "privado", entre "propriedade" e "uso", entre recursos "abertos" e "fechados", entre "tradicional" e "moderno", menosprezando a dinâmica das situações concretas produzidas pelos povos e grupos tradicionais nas suas relações sociais com seus antagonistas históricos. (p. 20)
}

A essa observação pode-se agregar o binômio rural/urbano, que acaba sendo cristalizado pelo ordenamento jurídico através do Decreto-Lei $\mathrm{n}^{\circ} 311$ de 02 de março de 1938, o qual estabelece, em seu artigo 3, que toda sede municipal tem a categoria de cidade. Passadas mais de seis décadas da origem dessa normativa, as cidades, hoje, enfrentam dificuldade de gestão tanto pela dimensão demográfica que ocupam, como pela importância econômica que exercem no cenário brasileiro. No entanto, a normativa constituída durante o Estado Novo continua vigente. Com isso, Souza (2009) sinaliza a inadequação desta normativa para a atual conjuntura do país, sobretudo, no que se refere ao crescimento do número de cidades e à mobilização motivada por políticas de ocupação do espaço. No gráfico 01 é possível visualizar e comparar o aumento do número de cidades por regiões. 
GRÁFICO 01 - Quantidade de cidades nos anos de 1950 e 2000.

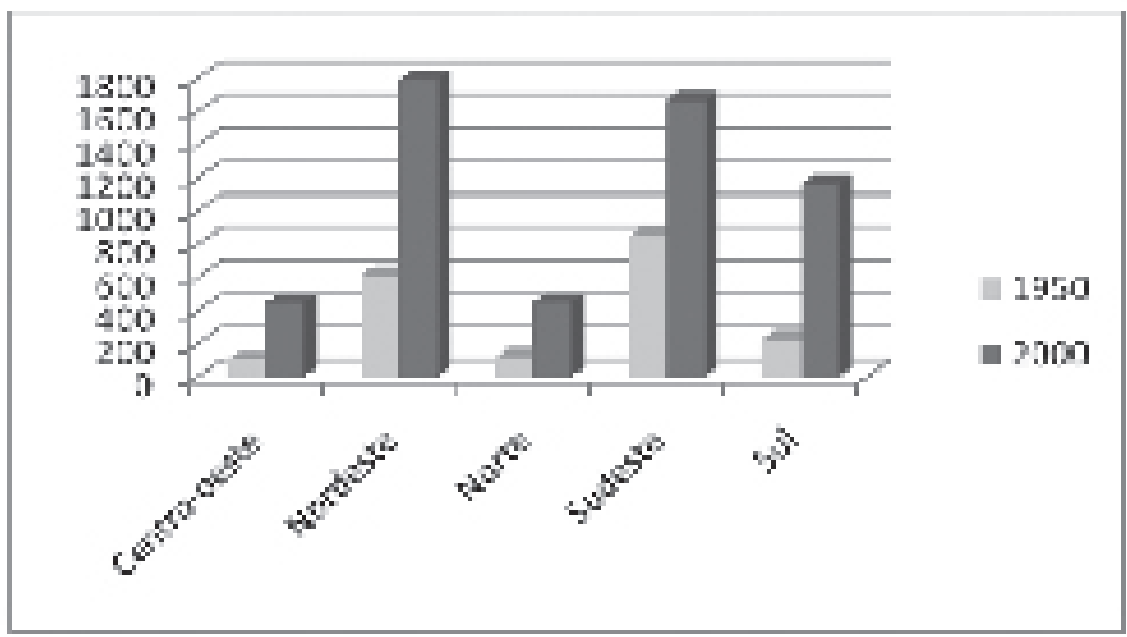

FONTE: SOUZA, 2009.

O mais antigo censo demográfico disponibilizado pelo IBGE refere-se ao recenseamento do ano de 1950. Este apontou o total de 1.887 cidades, enquanto para o censo do ano de 2000 o total saltou para 5.507. No entanto, o aumento do número de cidades não significa crescimento urbano, visto que neste critério não são consideradas variáveis de cunho urbanístico, o que significa dizer que a normativa não apresenta distinção entre um município pequeno e um grande centro urbano (Souza, 2009).

É nesse sentido que Veiga (2002) aponta a necessidade de revogação do Decreto-lei n³11/1938, que define cidade toda sede municipal. $\mathrm{O}$ autor sugere a adoção de critérios adotados por outros países como Portugal, que determina a existência de, no mínimo, oito mil eleitores e um total mínimo de dez equipamentos considerados urbanos, como teatro, transporte coletivo, bibliotecas, museus, dentre outros. Para sustentação desta argumentação, Veiga utiliza o exemplo díspar de tamanho da cidade como a de União da Serra no Rio Grande do Sul, que foi criada com apenas 18 habitantes e ainda no censo demográfico de 2001 habitavam 286 pessoas (Souza, 2009).

Outro estudo de pequenas cidades da Amazônia refere-se ao que foi desenvolvido por Sousa (2009). Este autor pesquisou o município de Prainha e o processo de constituição do Plano Diretor desse município, apresentando dados que corroboram essa especificidade no modo de vida 
das cidades amazônicas, que são permanentemente influenciadas pelo ambiente que as cerca. Assim se pronuncia o autor sobre a "ruralidade" da cidade de Prainha:

(...) na cidade de Prainha, no Oeste do Pará, (...) este pesquisador ouviu várias vezes homens, mulheres e jovens manifestarem-se que iriam passar o final de semana na região de várzea ou nas colônias, onde várias famílias possuem sítios, cultivando a plantação nos roçados ou, nas áreas de várzeas com a criação de búfalos e até mesmo a pesca de subsistência ou profissional para o sustento local. (p. 88).

Mais adiante, o autor amplia essa visão para outras cidades ao redor de Prainha, que apresentam uma dinâmica similar. Entre elas estariam cidades como Almeirim, Monte Alegre e Santarém, “(... ) todas com expressão de urbanização difusa, ou seja, confundem-se com os modos de vida da floresta e os modos de vida do campo rural." (SOUSA, 2009, p. 136). Constata-se, nesse contexto, que estas cidades ainda têm em sua dinâmica interna forte influência de atividades como o extrativismo, agricultura familiar, agropecuária, e a pesca artesanal (Sousa, 2009).

Estas cidades localizam-se no meio da floresta, entre rios e igarapés diversos. Um exemplo disso é apontado por Sousa (2009), quando chama a atenção para o fato de que até mesmo as populações urbanas estão familiarizadas ao modo de vida rural, vivendo em "(...) embarcações ao longo dos rios, dos igarapés; pessoas que sabem conviver com os campos alagadiços ou várzeas por um período longo de cada ano devido às cheias pluviais (...)" (SOUSA, 2009, p. 137). Mais adiante, Sousa (2009) enfatiza o isolamento destas cidades na relação com outros centros urbanos, visto que pode demorar dias até "chegar a outros centros urbanos mais desenvolvidos, como é o caso da longa distância que separa a região do Baixo Amazonas, até a Capital do Estado, Belém do Pará" (SOUSA, 2009, p. 137).

Outra interessante característica dessas "cidades na floresta" seria a estrutura que apresentam em seu centro urbano: trapiche(s), delegacia, igrejas católica e protestante, os prédios públicos da prefeitura que dificilmente se estendem a mais de dois, para dar conta de suas secretarias municipais, o fórum, uma escola e um posto de saúde (SOUSA, 2009). Todo esse "aglomerado urbano" localiza-se em torno de uma praça que, regra geral, é a única da cidade. O restante do espaço "urbano" configurase em algumas poucas ruas, a maior parte não asfaltada, sendo cobertas, 
em geral, ou por terra batida, ou por piçarra ou por bloquete; o restante do município caracteriza-se por rios ou outros corpos d' água e florestas em geral $^{4}$.

Cardoso e Lima (2006) também apresentam uma interessante opinião a respeito das tipologias de cidade na Amazônia. Estes autores empreenderam uma investigação científica em alguns municípios da Amazônia Oriental, a saber: Medicilândia, Placas, Novo Repartimento, Igarapé-Miri, Baião, Cametá e Limoeiro do Ajuru. Como resultado de suas investigações, propõem a existência de diversas tipologias de ocupação do território nos municípios amazônicos: as sedes municipais em si mesmas (as cidades no sentido colocado pelo Decreto-Lei n³11/1938, recém citado), vilas ribeirinhas, agrovilas, projetos de assentamento, reservas ambientais, reservas indígenas e fazendas (CARDOSO E LIMA, 2006, p. 64). Mais adiante, os autores observam a existência de dois padrões gerais de tipologias de cidades: um relacionado ao rio, outro às estradas.

No padrão relacionado ao rio estariam as cidades mais antigas, que desempenharam um importante papel no processo de gênese de um mercado local e regional, assim como de "inserção" da Amazônia no mercado nacional e internacional, na medida em que desempenharam o papel de pontos de escoamento da produção nos grandes ciclos que fizeram parte da história econômica da região (drogas do sertão, borracha, grandes projetos). Essas cidades apresentavam um perfil extrativista e rural e, dependendo da sua história específica, seguiram padrões diferenciados de ocupação do território. Como exemplo, cita-se a cidade de médio porte de Santarém, que sofreu forte influência com a implantação de grandes projetos de desenvolvimento nacional, a cidade de Belém, que se tornou a capital estadual, assumindo um aspecto diferenciado das outras cidades da região (é uma das duas cidades consideradas de grande porte da região amazônica), e as diversas cidades de pequeno porte que continuam a desenvolver as atividades rurais e extrativistas, entre outros tipos de cidade localizadas à beira de corpos d'água (CARDOSO E LIMA, 2006, p. 66).

Faz-se cogente observar a importância das feiras em uma região geograficamente tão isolada, visto que ocupam um papel que irá suprir as necessidades de abastecimento da população. As cidades e vilas, através do espaço da feira, comercializavam os produtos oriundos da zona rural,

4 Participei de diversas pesquisas sobre a Amazônia, visitando municípios do rio Purus-AM (como Tapauá, Lábrea, Canutãma, Beruri etc), Baixo Tocantins (Igarapé Miri, Cametá, Oeiras), Zona Costeira (Bragança, Primavera, Vigia, Colares etc), sendo que, em todos esses municípios, o padrão recém-citado repete-se com pouquíssimas variações. 
transformando esses espaços em pontos de grande interesse e convergência nas aglomerações urbanas “... à beira dos rios, articulando a população ribeirinha de diferentes localidades, entre si e com a população urbana, ampliando as alternativas de consumo da população em geral." (p. 67).

Igualmente, faz-se imperioso ressaltar que o principal meio de transporte das populações amazônicas, até a década de 1980, efetivavase por via fluvial. Evidencia-se, assim, que as cidades localizadas à beira de rios desempenharam um importante papel regional, visto que disponibilizavam uma infraestrutura mínima para a população em geral, especialmente através de escolas e postos de saúde ou hospitais (Cardoso e Lima, 2006, p. 67).

O padrão relacionado à estrada surgiu com o avanço do modelo de desenvolvimento e integração regional sobre a Amazônia, especialmente em meados do século XX, através da implementação de grandes projetos na região (mineradoras, hidrelétricas e projetos de assentamento do INCRA notadamente). Tais projetos necessitavam de uma via de escoamento para a sua produção, forçando a criação de estradas, que, em seu decorrer, serviam de local para o surgimento de diversas aglomerações que, com o tempo, transformaram-se em cidades. Os autores também observam o importante papel que estas cidades desempenharam na oferta de serviços básicos como educação e saúde à população rural e até mesmo urbana dos municípios ao redor. "Nesse sentido, a acessibilidade rodoviária torna-se um fator essencial no desenvolvimento de uma agrovila, da mesma forma que a acessibilidade fluvial é determinante..." para as vilas ribeirinhas (Cardoso e Lima, 2006, p. 68).

Cardoso e Lima (2006) concluem seu texto corroborando a ideia de relativização da dicotomia urbano-rural, observando que

\begin{abstract}
A clara hierarquização das cidades (capital, cidade, vila) e a distinção entre modos de vida rural e urbanos existentes no passado foram perdidas após as transformações ocorridas nas condições de acessibilidade ... na dinâmica econômica ... e a redefinição do conceito de cidade... (quando passam a ser cidade todas as sedes de município) (p. 90).
\end{abstract}

Em uma reflexão similar, Pereira (2006), ao remeter-se à história da Amazônia, questiona "o pensamento que associa cidade e urbanização como resultantes de uma evolução linear e cumulativa (da aldeia indígena à metrópole)" (PEREIRA, 2006, p. 28-29). O autor também considera "um 
erro chamar de urbanização as aglomerações surgidas durante o período colonial, ou mesmo considerar aglomerações como cidade." (PEREIRA, 2006, p. 28-29).

Nesse sentido, Pereira (2006) amplia as tipologias de cidade propostas por Cardoso e Lima (2006), sugerindo a existência de uma rede urbana amazônica, resultante do período dos grandes projetos (década de 60 em diante). Segundo o referido autor, "[e]sse período marca a presença definitiva do Estado [na Amazônia], através de um conjunto de programas, projetos, instituições, ideologias e ações políticas." (PEREIRA, 2006, p. $31)$.

O autor dá continuidade ao seu texto construindo a reflexão de que as cidades médias apresentam um importante papel dentro do contexto regional por diversos fatores, entre eles o de figurarem como espaço para a disponibilização de uma infraestrutura urbana mínima, notadamente relacionada à área da saúde e seguridade social. Outra conclusão do autor refere-se à definição de três modalidades de cidades médias:

\footnotetext{
... as cidades médias às margens de estrada apresentam melhor conexão com outras cidades e maior facilidade de acesso para a população migrante, Marabá e Castanhal, por exemplo; as cidades médias às margens dos rios guardam características com o padrão dendrítico e têm no rio seu principal meio de articulação com as cidades menores de sua respectiva mesorregião, como é o caso de Santarém; e as cidades médias capitais estaduais (Rio Branco e Porto Velho), que por sua vez apresentam os melhores indicadores no que diz respeito à oferta de bens e serviços à sua população (p. 49, grifo nosso).
}

Este autor observa que, a partir da década de 1960, o índice anual de urbanização da Amazônia supera o de todas as outras regiões do Brasil (Pereira, 2006, p. 31). Mais adiante, Pereira (2006, p. 41) lança mão de dados estatísticos, especialmente de mobilidade demográfica, para observar que as cidades médias da Amazônia têm uma média de urbanização de $86 \%$, superior à da média nacional, que é de $81,2 \%$, concluindo que a urbanização na Amazônia é uma situação dada (Pereira, 2006, p. 31). Seguem abaixo alguns dos dados analisados por Pereira (2006). 
Tabela 1: População residente na Região Metropolitana de Belém

\begin{tabular}{|c|c|c|c|}
\hline Município & População geral & População urbana & Geral/urbana (\%) \\
\hline Pará & 6.192 .307 & 4.120 .693 & 66,55 \\
\hline RMB & 1.795 .536 & 1.754 .816 & 97,73 \\
\hline Belém & 1.280 .614 & 1.272 .354 & 99,35 \\
\hline Ananindeua & 393.569 & 392.657 & 99,77 \\
\hline Marituba & 35.546 & 20.912 & 58,83 \\
\hline Benevides & 74.429 & 64.884 & 87,18 \\
\hline SantaBárbara & 11.378 & 4.009 & 35,23 \\
\hline
\end{tabular}

Fonte: Pereira, 2006, p. 36 (apud IBGE, Censo Demográfico 2000).

Tabela 2: População das capitais da Região Norte - 2000

\begin{tabular}{|l|l|l|l|}
\hline Capital & Total & Urbana & Rural \\
\hline Belém & 1.280 .614 & 1.272 .354 & 8.260 \\
\hline Boa Vista & 200.568 & 197.098 & 3.470 \\
\hline Macapá & 283.308 & 270.628 & 12.690 \\
\hline Manaus & 1.405 .835 & 1396.768 & 9.067 \\
\hline Palmas & 137.355 & 134.179 & 3.176 \\
\hline Porto Velho & 334.661 & 273.709 & 60.952 \\
\hline Rio Branco & 253.059 & 226.298 & 26.761 \\
\hline Total & 3.895 .400 & 3.771 .034 & 124.366 \\
\hline
\end{tabular}

Fonte: Pereira, 2006, p. 37 (apud IBGE, Censo Demográfico 2000). 
Tabela 3: Distribuição da População da Região Norte,
segundo classes de município

\begin{tabular}{|l|l|l|l|l|l|l|l|l|l|}
\hline \multicolumn{1}{|c|}{ Habitantes } & PA & AM & RO & RR & AC & AP & TO & Total & \multicolumn{1}{c|}{$\%$} \\
\hline Até 5.000 & 03 & 0 & 05 & 01 & 03 & 06 & 80 & 98 & 21,83 \\
\hline 5.001 a 10.000 & 15 & 09 & 10 & 09 & 07 & 04 & 37 & 91 & 20,27 \\
\hline 10.001 a 20.000 & 42 & 25 & 20 & 04 & 07 & 03 & 12 & 113 & 25,17 \\
\hline 20.001 a 50.000 & 60 & 22 & 11 & 0 & 03 & 01 & 07 & 104 & 23,16 \\
\hline 50.001 a 100.000 & 17 & 05 & 04 & 0 & 01 & 01 & 01 & 29 & 6,46 \\
\hline 100.001 a 500.000 & 05 & 0 & 02 & 01 & 01 & 01 & 02 & 12 & 2,67 \\
\hline Mais de 500.000 & 01 & 01 & 0 & 0 & 0 & 0 & 0 & 02 & 0,45 \\
\hline Total & 143 & 62 & 52 & 15 & 22 & 16 & 139 & 449 & 100,00 \\
\hline
\end{tabular}

Fonte: Pereira, 2006, p. 38 (apud IBGE, Censo Demográfico 2000).

A interpretação dos dados construída por Pereira (2006) entende que a urbanização da Amazônia é um fato dado e sua elevação é inevitável. Como instrumento interpretativo de seus dados, o autor em tela utiliza conceitos como cidades médias (p. 23 e 24, entre outras), rede urbana, rede dendrítica, rede urbana regional, rede urbana complexa ${ }^{5}$, urbanização (p. 34), fronteira urbana (p. 31), urbanização concentrada (p. 35), centros urbanos na concepção da Teoria dos Lugares Centrais (p. 39), entre outros conceitos. Com sua análise, Pereira (2006) leva a cabo a conclusão de que há uma tendência de aumento populacional nas sedes de cidades, ligada à proliferação de pequenas cidades e ao aumento de importância de cidades médias no contexto econômico regional, constituindo-se como novos vetores de crescimento econômico e demográfico.

Ocorre que as tabelas demonstram como as populações citadinas vêm aumentando mas, no entanto, não necessariamente induzem ao entendimento proposto por Pereira (2006) de que existe uma urbanização da Amazônia. Por outro lado, Nunes (2008), ao analisar dados semelhantes, chega a resultados similares em alguns momentos, contudo, controversos 5 Estes conceitos relativos ao termo "rede" estão concentrados da página 26 à página 32; contudo, repetem-se em outras partes do texto de Pereira (2006), especialmente os conceitos de rede urbana e rede urbana regional. 
em outros momentos.

Desde o início de seu texto, Nunes (2008) observa que "a tendência de generalização de relações monetarizadas no meio urbano não tem implicado, na região [amazônica], uma ruptura com formas tradicionais de ligação entre os modos urbano e rural" (NUNES, 2008, p. 41), ou seja, a interface entre o urbano e o rural "reconstrói eternas 'formas primárias' de sociabilidades, na medida em que avançam as "formas secundárias"" (NUNES, 2008, p. 41). Em outras palavras, Nunes (2008) quer dizer que, apesar do avanço da fronteira urbana sobre a floresta amazônica, a maior parte do modo de vida de seus habitantes permanece, resultando em um modo de vida específico que mescla velhas formas de sociabilidade e modo de vida (as formas primárias, nas palavras de Nunes, 2008) com novas formas de sociabilidade e modo de vida (as formas secundárias, nas palavras de Nunes, 2008), permitindo que alguns dos valores rurais permaneçam em espaços "urbanos".

Mais adiante, o autor ratifica esta visão ao afirmar que

na aglomeração urbana, embora se observe uma tendência para a generalização das relações contratuais, monetarizadas, ocorre simultaneamente a reprodução de vínculos tradicionais de convivência social, o que não implica automaticamente uma radical ruptura com modos de vida rurais. (NUNES, 2008, p. 48)

Assim, ao analisar os 19.913.335 habitantes dos 750 municípios da Amazônia, Nunes (2008) chama a atenção para o fato de que, desse total de habitantes, 31,15\% vivem em áreas rurais, ou seja, "ainda há uma importante parte de moradores em áreas não urbanas" (p. 49). Dando continuidade à sua análise, o autor relativiza os critérios de interpretação dos dados, observando que, muitas vezes, os moradores urbanos "habitam pequenas cidades, cujo ambiente aproxima-se mais das características de povoados do que propriamente de cidades, no sentido mais usual do termo" (p. 49). Em outras palavras, o autor tentou relativizar o conceito de cidade e de morador urbano que é adotado pelo IBGE6

Mais adiante, o autor acaba por se contradizer, ao afirmar que "o fenômeno da urbanização é uma evidência também na Amazônia" (p. 49); ou seja, Nunes (2008) acaba apresentando a mesma interpretação que Pereira (2006). Ocorre que este posicionamento contraditório é esclarecido

$6 \mathrm{O}$ conceito de habitante urbano refere-se ao mesmo conceito formulado pelo Decreto-Lei n⿳311/1938, em que se considera urbana toda sede de município, independente de suas características. 
no decorrer do texto, pois Nunes (2008) distingue-se de Pereira (2006) ao relativizar o conceito de urbanização, tentando adaptá-lo para a região amazônica. Como resultado dessa relativização, o autor apresenta conceitos e dados estatísticos de maneira distinta do que usualmente se faz.

Nunes (2008) analisa dados diversos; contudo, os mais relevantes para este empreendimento reflexivo podem ser condensados na tabela abaixo:

(2000)

Tabela 04: Amazônia Legal - rede urbana por tamanho

\begin{tabular}{|c|c|c|c|c|c|c|c|}
\hline $\begin{array}{c}\text { Classe } \\
\text { de tamanho }\end{array}$ & $\begin{array}{c}\mathrm{N}^{\circ} \text { de } \\
\text { municípios }\end{array}$ & $\begin{array}{c}\text { População } \\
\text { total }\end{array}$ & $\begin{array}{c}\text { População } \\
\text { urbana }\end{array}$ & $\begin{array}{c}\text { População } \\
\text { rural }\end{array}$ & $\begin{array}{c}\text { Pop. } \\
\text { total \% }\end{array}$ & $\begin{array}{c}\text { Pop. } \\
\text { urbana \% }\end{array}$ & $\begin{array}{c}\text { Pop. } \\
\text { rural \% }\end{array}$ \\
\hline $\begin{array}{c}\text { Mais de } \\
1.000 .000\end{array}$ & 2 & 2.683 .675 & 2.666 .339 & 17.318 & $13,48 \%$ & $19,45 \%$ & $0,28 \%$ \\
\hline $\begin{array}{c}500.000 \\
-1.000 .000\end{array}$ & 1 & 867.690 & 834.968 & 32.722 & $4,36 \%$ & $6,09 \%$ & $0,53 \%$ \\
\hline $\begin{array}{c}100.000 \\
-500.000\end{array}$ & 17 & 3.688 .751 & 3.275 .363 & 413.388 & $18,52 \%$ & $23,89 \%$ & $6,66 \%$ \\
\hline $\begin{array}{c}50.000 \\
-100.000\end{array}$ & 44 & 3.056 .782 & 1.993 .358 & 1.063 .424 & $15,35 \%$ & $14,54 \%$ & $17,14 \%$ \\
\hline $\begin{array}{c}20.000 \\
-50.000\end{array}$ & 161 & 4.835 .867 & 2.647 .852 & 2.188 .015 & $24,28 \%$ & $19,31 \%$ & $35,27 \%$ \\
\hline $\begin{array}{c}\text { Menos } \\
\text { de } 20.000\end{array}$ & 525 & 4.780 .588 & 2.291 .676 & 2.488 .912 & $24,01 \%$ & $16,72 \%$ & $40,12 \%$ \\
\hline Total & 750 & 19.913 .353 & 13.709 .556 & 6.203 .779 & $100,00 \%$ & $100,00 \%$ & $100,00 \%$ \\
\hline
\end{tabular}

Fonte: IBGE. Censo Demográfico 2000 apud Nunes (2008, p. 51).

Antes de dar início à interpretação e análise da tabela, faz-se imperioso observar que Nunes (2008) dá continuidade ao seu texto através da exposição de dados e argumentos sólidos e diversos, abordando temas e conceitos como globalização, PIB, industrialização entre outros. Contudo, não cabe aqui detalhar tais argumentos, limitando-se o texto à dicotomia 
urbano/rural, explorada através da tabela acima exposta e a algumas citações que virão a seguir. Assim, Nunes (2008) observa que os três primeiros municípios com o maior número de habitantes (respectivamente Belém, Manaus, São Luis) concentram um grande contingente de habitantes da região, especialmente aqueles da área urbana; contudo, $48,29 \%$ da população total da região concentram-se nos municípios que estão nas faixas entre 20.000-50.000 (161 municípios) e menos de 20.000 (525 municípios), os quais representam 91,47\% dos municípios da Região Norte. Das populações desses municípios, estima-se que somente 36,03\% sejam urbanas e 75,39\% sejam rurais (NUNES, 2008, p. 49-50).

Com isso, Nunes (2008) começa a levar a cabo a sua conclusão, observando que, apesar de considerar a "cidade" como um ambiente social que por excelência é mercantilizado, na medida em que a existência social urbana é praticamente regulada por relações monetárias, as cidades amazônicas de pequeno porte não se ajustam a esse padrão, já que não se apresentam como um espaço social onde o modelo de equivalência seja hegemonicamente material e simbolicamente baseado nas trocas aí realizadas (NUNES, 2008, p. 54-55). ${ }^{7}$

Segundo o autor em tela, as cidades amazônicas são marcadas por características regionais (economia mineral, extrativismo, regiões de fronteira etc), formando uma rede de "cidades complexas e heterogêneas que, dada a precariedade da infraestrutura de transporte, têm baixa conexão e fluxos dispersos, muitas vezes polarizados por centros extrarregionais" (Nunes, 2008, p. 55). Com isso, o autor observa que é a convivência entra as esferas mercantil e não mercantil "que confere especificidade ao fato urbano na região, exigindo sua decodificação para compreendêla como fenômeno cultural" (NUNES, 2008, p. 55). Em outras palavras, o autor chama a atenção para a necessidade de se adaptar o conceito de urbano para a região amazônica, na medida em que este conceito assume aspectos culturais dentro dessa região tão dominada pela lógica rural e socioambiental.

À guisa de conclusão, o autor observa a necessidade de um olhar mais holístico para as especificidades da Amazônia, pois:

Na relação entre "redes" (sociabilidades primárias) e "aparelhos" (sociabilidades secundárias), poderia inserir-se a lógica social da região na sua totalidade

7 Vale observar que o autor, a princípio, caracteriza a área urbana como um espaço mercantil, industrial, de produção e consumo, enquanto a área rural amazônica é caracterizada por sua veia não mercantil, baseada em trocas mais simbólicas do que monetárias. 
urbana/rural. Isso porque o urbano na Amazônia é heterogêneo: é uma mistura de estilos de vida rural e vida na aglomeração, reforçada pela enorme diversidade de produtos extrativos que compõem o conjunto de bens que circulam no meio urbano (Nunes, 2008, p. 56. Grifo nosso.).

Mais adiante, o autor conclui o texto, relativizando o conceito de urbanização, atrelando-o à ideia de cultura, ou seja, regionaliza-se o conceito de urbano para a Amazônia, resultando em cidades ou aglomerados urbanos permeados por lógicas rurais. Nas palavras maestrais de Nunes:

Entretanto, mesmo que a urbanização dependa, em suas características mais essenciais, de condições e fatores históricos preexistentes ao desenvolvimento industrial ou mesmo de elementos amplamente independentes da concentração industrial e do emprego na manufatura - caso das cidades capitais - , não é fora de propósito considerar o fenômeno de urbanização como um dado "cultural", por impregnar as mentalidades, independentemente do fato de as populações morarem no campo ou na cidade. A circulação de valores novos nas cidades talvez justifique a importância que se deva dar ao espaço urbano como núcleo difusor de inovações, tanto na produção econômica, como também, e, sobretudo, na produção de formas simbólicas. Essa consideração adquire maior pertinência se olharmos o fantástico desenvolvimento dos meios de comunicação nos últimos anos do século $\mathrm{XX}$, que alterou radicalmente a noção de tempo e de espaço, dimensões particularmente estratégicas para os povos que vivem a floresta. Nesse sentido, as pesquisas que precisam ser feitas sobre a disposição dos elementos no quadro urbano e sobre as sensações que eles provocam exigem hipóteses arrojadas, que convém corrigir constantemente à luz da experiência, pela crítica e pela autocrítica (p. 57).

À guisa de conclusão, evidencia-se a reflexão que, desde o início deste trabalho, tem-se tentado construir: a noção de rural e urbano é construída socialmente; consequentemente, sofrerá intensas influências regionais e, por que não, pensar esta dicotomia como regionalmente construída. Desta forma, existe a possibilidade de se importar conceitos desta dicotomia que não se aplicam à região amazônica, criando-se a necessidade de o Estado, de uma maneira geral (Poderes Executivo, Legislativo e Judiciário; esferas Federal, Estadual e Municipal), tomar das especificidades locais no planejamento urbano. Nesse sentido, conclui-se que a legislação, quando se fundamenta no binômio rural/urbano, adentra um campo conceitual muito tênue e até mesmo inexistente em alguns casos; 
com isso, o ordenamento jurídico nem sempre consegue regular a realidade socioambiental amazônica levando em consideração as especificidades regionais dos conceitos em questão.

\section{CONCLUSÃO}

Através de Bourdieu (2004), foi possível demonstrar que o campo jurídico configura-se em uma arena de disputa na qual as populações tradicionais estão excluídas. Demonstrou-se, ainda, que o modus operandi presente nesse campo diferencia-se do modus operandi dessas populações, resultando em um campo jurídico/Direito que não se aplica às populações tradicionais. Em outras palavras, o Direito (entendido como um espaço de disputa pelo direito de dizer o direito, segundo Bourdieu, 2004) que é produzido por legisladores, juízes, advogados, juristas etc, não se aplica à realidade amazônica, pois estes atores, que produzem o capital jurídico, detêm um modo de vida diferenciado das populações tradicionais. Tal inaplicabilidade se expressa, especialmente, quando regula a relação entre sociedade e ambiente, pois, na medida em que as populações tradicionais têm um modo de vida diferenciado daqueles que produzem leis e jurisprudências, estas não se aplicam ao modo de vida dessas populações. Com efeito, algumas das normas de Direito Ambiental Urbanístico encaixam-se nesse modelo de inaplicabilidade, especialmente por se fundarem no binômio rural/urbano que deve ser relativizado dentro do contexto socioambiental amazônico.

Nesse sentido, o trabalho conclui que: 1) existe uma crise dos padrões jurídicos tradicionais em função do pluralismo jurídico emergente das práticas socioambientais das comunidades amazônicas; 2) o mosaico de realidades que compõem o contexto amazônico, do ponto de vista ambiental e social, mostra-se deveras complexo e peculiar na relação comparativa com os demais cenários regionais, normalmente de onde emana a construção das normas que regulamentam o cenário de direitos no Brasil. Desse modo, as cidades na Amazônia evidenciam as dificuldades no uso das normativas que regulamentam o espaço urbano, assim como o definem; 3) em relação a essa crise de padrões jurídicos, surge a necessidade de se relativizar, entre outros, o binômio rural/urbano dentro do contexto amazônico (VEIGA, 2002; SOUZA, 2009; ALMEIDA, 2008). Diante das reflexões aqui apresentadas, surge, então, o questionamento: existe um direito ambiental urbanístico da Amazônia ou na Amazônia? 


\section{REFERÊNCIAS}

ALMEIDA, Alfredo Wagner B. Arqueologia da Tradição. In: Leis do Babaçu Livre: Práticas Jurídicas das Quebradeiras de coco babaçu e normas correlatas. SHIRAISHI NETO, Joaquim. Manaus: PPGSCAUFAM/Fundação Ford, 2006.

ALMEIDA, Alfredo Wagner Berno de. Terras tradicionalmente ocupadas: terras de quilombo, terras indígenas, babaçuais livres, castanhais do povo, faxinais e fundos de pasto. 2. ed. Manaus: Editora da Universidade do Amazonas, 2008.

ALMEIDA, Mauro. Quem são os povos da floresta? Cadernos SBPC 30. Povos da Floresta: Cobertura jornalística feita a partir de conferências e mesas-redondas apresentadas na 59 Reunião Anual da Sociedade Brasileira para o Progresso da Ciência (SBPC). 2007.

ARRUDA, Rinaldo. "Populações Tradicionais" e a proteção de recursos naturais em Unidades de Conservação. In: Ambiente \& Sociedade, ano II, n 5, 1999.

BOURDIEU, Pierre. O poder simbólico. Lisboa: Diefel, 1989.

BOURDIEU, Pierre. A força do direito: elementos para uma sociologia do campo jurídico. In: $O$ poder simbólico. Tradução Fernando Tomaz (português de Portugal) - 7 ed. - Rio de Janeiro; Bestrand Brasil, 2004, p. $209-254$.

CASTRO, E. M. R. ; MARIN, R. A. Negros do Trombetas: Guardiões de Matas e Rios. 2a. ed. BELEM: CEJUP, 1993. 278 p.

CARDOSO, A. C. D.; LIMA, J. J. F. Tipologia e padrões de ocupação urbana na Amazônia oriental: para que e para quem? In: CARDOSO, Ana Cláudia Duarte. (Org.). O Rural e o urbano na Amazônia: diferentes olhares e perspectiva. Belém: EDUFPA, 2006. p. 55-93.

CUNHA, Manoela Carneiro. Populações Tradicionais e a Convenção da Diversidade Biológica. Estudos Avançados, 1999. 
CUNHA, Manoela Carneiro da; ALMEIDA, Mauro W. B. Populações tradicionais e conservação ambiental. In: CAPOBIANCO, João Paulo Ribeiro et al. Biodiversidade na Amazônia brasileira: avaliação e ações prioritárias para a conservação, uso sustentável e repartição de benefícios. São Paulo, Estação Liberdade: Instituto Socioambiental, 2001.

DIEGUES, Antonio Carlos S. Populações Tradicionais em Unidades de Conservação. In: VIEIRA, Paulo Freire; MAIMON, Dália (Org.). As Ciências Sociais e a Questão Ambiental: Rumo à Interdisciplinaridade. Belém: NAEA/UFPA, 1993.

DIEGUES, Antonio Carlos S. O mito moderno da natureza intocada. São Paulo: Editora HUCITEC, 1994.

DIEGUES, Antonio Carlos S. O mito do paraíso desabitado nas florestas tropicais brasileiras. In: CASTRO, Edna \& PINTON, Florence (orgs). Faces do trópico úmido: conceitos e questões sobre desenvolvimento e meio ambiente. Belém: CEJUP, UFPA-NAEA, 1997.

LIMA, Deborah; POZZOBON, Jorge. Amazônia socioambiental. Sustentabilidade ecológica e diversidade social. In: Estudos Avançados n 19 (54), 2005.

MAUES. Raymundo Heraldo. Uma outra invenção da Amazônia: religiões, histórias, identidades. Belém: CEJUP, 1999.

MEIRELLES FILHO, João Carlos. O livro de ouro da Amazônia: mitos e verdades sobre a região mais cobiçada do planeta. Rio de Janeiro: Ediouro, 2004.

NUNES, B. F. A interface entre o urbano e o rural na Amazônia brasileira. In: Edna Castro. (Org.). Cidades na Floresta. 1 ed. São Paulo: Annablume, 2008, v. 1, p. 41-58.

PEREIRA, J. C. M. . A Urbanização da Amazônia e o papel das Cidades Médias na Rede Urbana Regional. In: Ana Claúdia Duarte Cardoso. (Org.). O Rural e o Urbano na Amazônia: diferentes Olhares em Perspectivas. 1 
ed. Belém (PA): Editora Universitária UFPA, 2006, v. 1.000, p. 1-215.

SANTILLI, Juliana. Povos Indígenas, quilombolas e populações tradicionais: a construção de novas categorias jurídicas. In: RICARDO, Fany (Org.). Terras Indígenas e Unidades de Conservação da Natureza: o desafio das sobreposições. São Paulo: Instituto Socioambiental, 2004.

SANTILLI, Juliana. Socioambientalismo e Novos Direitos. São Paulo: Peirópolis, 2005.

SOUSA, F. H. Aspectos jurídicos do plano diretor municipal de prainha: região oeste do estado do Pará - baixo Amazonas. Dissertação (Mestrado) - Universidade da Amazônia, Programa de Pós-Graduação em Direito. Belém, 2009. Mimeo.

SOUZA, Cleide. Amazônia, para além da discussão entre Campo e Cidade: O município de Tapauá/AM Em Foco. Dissertação (Mestrado) - Universidade da Amazônia, Núcleo de Qualidade de Vida e Meio Ambiente Urbano, Programa de Pós-Graduação em Desenvolvimento e Meio Ambiente Urbano. Belém, 2009. Mimeo.

VEIGA, J. E. . Cidades Imaginárias. 2a. ed. Campinas, SP: Editora Autores Associados, 2002. v. 1. 198 p.

Artigo recebido em: 23/08/2018. Artigo aceito em: 18/05/2018.

\section{Como citar este artigo (ABNT):}

CAÑETE, T. M. R.; CAÑETE, V. R. INAPLICABILIDADES DO DIREITO NA AMAZÔNIA: POR UM DIREITO AMBIENTAL URBANÍSTICO DA AMAZÔNIA E NÃO NA AMAZÔNIA. Veredas do Direito, Belo Horizonte, v. 15, n. 32, p. 117-142, mai./ago. 2018. Disponível em: <http://www.domhelder.edu.br/revista/index.php/veredas/ article/view/1153>. Acesso em: dia mês. ano. 